\title{
LA CREATIVIDAD COMO ASPECTO DE UN REPLANTEAMIENTO DE LA TEORÍA SOCIOLÓGICA DE LA ACCIÓN
}

\author{
CREATIVITY AS AN ASPECT OF A RETHINKING OF THE \\ SOCIOLOGICAL THEORY OF THE ACTION
}

\author{
Javier L. Cristiano*
}

\section{Resumen}

Este artículo presenta un enfoque de la creatividad de la acción que, sin renunciar a los logros alcanzados por diversas tradiciones sociológicas, apuesta por la imaginación como clave filosófica complementaria para continuar su desarrollo. Se diagnostica primero el lugar restringido que la creatividad ha tenido en la sociología de la acción; se ofrece después una precisión de "creatividad", a partir de la noción de "contingencia"; ulteriormente se propone un esquema general para situar la imaginación en distintos niveles de la acción; y, finalmente, se muestran tres caminos de desarrollo posible, según se haga de la imaginación un fenómeno de la conciencia, del lenguaje o de la psique.

\section{Palabras clave}

Imaginación, contingencia, acontecimiento, cambio social.

\section{Abstract}

This article approaches creativity of action. Not discarding the achievements of various sociological traditions, the article takes imagination as a complementary philosophical key to develop the notion of "creativity". First, the article exposes the restricted place

\footnotetext{
* Doctor en Sociología de la Universidad Complutense de Madrid. Investigador adjunto al CONICET (Argentina) y profesor titular regular de Teoría Sociológica y Modernidad (Universidad Nacional de Córdoba, Argentina). Líneas de investigación: teoría sociológica, teorías de la acción social, lógicas del cambio social. Correo electrónico: javier.cristiano.m@gmail.com
} 
creativity has had in the sociology of action, and then it offers a more precise concept of "creativity", in light of the notion of "contingency". The article also describes the place for imagination at the different levels of action. Finally, the article shows three possible theoretical developments, taking imagination as a phenomenon of conscience, language or psyche.

\section{Keywords}

Imagination, contingency, event, social change.

\section{Introducción}

Corresponde empezar diciendo dos palabras acerca de las razones por las que el tema de la creatividad puede ser importante en el contexto de las teorías sociológicas de la acción ${ }^{1}$. En primer lugar, creo que la creatividad tiene interés en el marco más general de una teoría social crítica, si por tal teoría entendemos una que se interesa por su propia incidencia transformadora y que hace esto en

1 La tradición sociológica referida a la acción tiene, por supuesto, fronteras difusas; me refiero aquí globalmente, siguiendo la convención del campo, a la línea que se inicia con Max Weber y Pareto, que pasa por Schütz, Mead y Parsons, por las revueltas antiparsonianas de los años sesenta en Estados Unidos, expandidas de múltiples maneras hasta hoy, y por las sociologías de síntesis que Bourdieu, Giddens, Habermas y Alexander desarrollaron en los años ochenta, también prolongadas en diversos debates hasta el presente. No hay un texto único que presente este panorama en conjunto; pueden consultarse, para elaborarlo, los trabajos de Iglesias de Usell y Herrera Gómez (2005), Crespi (1997, cap. II), Dawe (2001) y García Selgas (1999). La obra del pragmatista alemán Hans Joas es la referencia explícita más importante al tema de la creatividad en el contexto de la sociología contemporánea de la acción (Joas, 2005). En otro lugar analicé las razones por las que el enfoque de Joas me parece limitado (Cristiano, 2010), y puede considerarse la propuesta de este artículo como el esbozo de un camino alternativo que de todos modos no es lógicamente excluyente. un sentido emancipatorio. Este punto resulta esencial porque basta una mínima atención para advertir que "creatividad" circula también en muchos contextos en el sentido contrario: como exaltación de unas capacidades agenciales que se acercan bastante a lo que en otro plano sería una celebración liberal del individuo. Además, una parte no menor de la teoría crítica de la acción parte del supuesto de que pensar la acción para la emancipación es concebirla atrapada en redes de poder que disminuyen, más que exaltar, sus capacidades. Por ello, inscribir el interés por la creatividad en el marco de una teoría crítica implica afirmar que la historia no termina allí, que no solo de dominación y poder vive la crítica (aunque, por supuesto, no pueda olvidarlos), pero asumiendo, al mismo tiempo, el desafío de no hacer de la creatividad una confirmación renovada del individuo liberal.

En segundo lugar, la cuestión de la creatividad es especialmente importante en el contexto de la sociedad actual; hecha la sociedad, según la mayoría de los diagnósticos, de apertura, dinamismo, complejidad, fluidez, multiplicidad y tópicos parecidos; hecha también de otras cosas, ciertamente (y de nuevo: de formas cada vez más acentuadas de dominación), pero particularmente de esos "declives de la institución" (Dubet, 2006) que cargan sobre el agente y sus capacidades un lastre mucho más pesado que 
la vieja sociedad "programada". Conectando este punto con el anterior, podría decirse que la emergencia de lo nuevo es un desafío hoy particularmente acuciante, también por razones normativas. Urge la acción creativa, no en un sentido trivial o genérico, sino en el sentido fuerte de crear nuevas formas de sociabilidad, nuevas instituciones, y por qué no, nuevas sociedades.

Si con estas premisas se echa un vistazo retrospectivo a las teorías de la acción que ha producido la sociología, se encuentra lo que me gusta llamar -con todos los cuidados y los matices del caso- "un sesgo reproductivista". Este consiste esencialmente en que a pesar de sus declaraciones explícitas, estas finalmente se muestran mejor preparadas y más eficaces para captar lo recurrente y lo estable en lugar de lo nuevo, en tres sentidos por lo menos. Uno, el interés liso y llano por la reproducción, por el modo en que la acción participa de circuitos reproductivos de las estructuras (piénsese, por ejemplo, en el primer Bourdieu). Otro, mucho más extendido, que podríamos llamar "sesgo rutinarista", donde la acción es presentada sobre todo como acción cotidiana, recurrente y reiterativa (pensemos en la importancia que lo habitual y lo cotidiano ha adquirido en casi todos los enfoques postparsonianos). Y un tercero, al que podríamos llamar "sesgo concertacionista", en el que el interés por la acción viene dominado por el interés en la coordinación de las acciones (podemos recordar aquí a Habermas, o a la etnometodología y su interés por la constitución "negociada" del orden, o al famoso "orden de la interacción" de Goffman).

Este sesgo es precisamente una inclinación o, si se prefiere, la coloración dominante de la teoría de la acción que propone la sociología. Y aunque no excluye obviamente la cuestión de la creatividad, sí quiero sugerir que esta indica precisamente el sesgo y la inclinación contraria. Todo lo ligada que se quiera a las rutinas, a la coordinación e, incluso, a la reproducción (que de hecho requiere cada vez más de "inventiva"), la creatividad indicaría el interés por el modo en que la acción puede convertirse en acontecimiento. En este sentido es en primer lugar y entre otras cosas posibles una invitación a leer las tradiciones teóricas de la sociología desde otro lugar, tratando de aprovechar su acopio de conocimiento desde un interés distinto del que hasta ahora ha sido el dominante. De una visión general y programática acerca de cómo hacerlo tratan las líneas que siguen.

\section{Creatividad e imaginación}

¿Qué entender, antes que nada, por "creatividad"? Quienes se han ocupado del tema (por ejemplo Joas, 2005; Williams, 2000; Tatarkiewickz, 1988) han advertido las trampas y ambigüedades de la palabra, de modo que más que responder la pregunta en forma sustantiva, quisiera proponer una semántica operativa para uso interno de este trabajo, a saber: que la creatividad consiste en la capacidad de producir contingencia. $\mathrm{La}$ contingencia, a su vez, siguiendo la definición de la lógica modal, sería lo que no es ni necesario ni imposible (Ferrater Mora, 1964). De modo que la creatividad podría definirse, en primera instancia, como la capacidad del actor de producir acciones que no son necesarias pero tampoco imposibles. Esto tiene la ventaja de dejar entre paréntesis la cuestión de "lo nuevo", que forma parte del significado primario de "creatividad" y que es el centro de uno de sus principales problemas, a saber: cómo se puede definir "lo nuevo".

Lo "contingente", de todos modos, es muy amplio, por lo que puede hacerse una distinción adicional entre lo que podríamos llamar "contingencia relativa" y "contingencia evenencial". Siendo lo contingente lo que no es necesario (es decir, lo que no está determinado), resulta relativamente contingente 
aquello que una vez sucedido puede remitirse, para su explicación, a lo que existía previamente. Por ejemplo, podemos decir que la acción de Pedro de usar determinada prenda es contingente (no era necesaria, aunque era posible) y que podemos "explicarla" a la luz de sus disposiciones (por ejemplo, un habitus orientado a la distinción). En cambio, decimos que una acción es evenencialmente contingente cuando una vez sucedida no puede remitirse, para su explicación, a lo que existía previamente. Nada hacía prever que Pedro actuaría de tal modo, y una vez ocurrida su acción, lo dado con anterioridad (por ejemplo sus disposiciones) no alcanza para subsumirla. Puede decirse que la acción es, en este sentido, un acontecimiento, y otro modo de decir lo mismo es afirmar que en tales casos la acción revela una posibilidad.

La creatividad puede, por lo tanto, ser también relativa o evenencial, y la distinción nos ayuda a precisar el diagnóstico anterior sobre las teorías de la acción. En general, las teorías de la acción han captado más y mejor la primera creatividad que la segunda, lo que no es extraño y más bien resulta lógico, puesto que lo que le importa como "ciencia" es precisamente "explicar", en el sentido más amplio de la palabra².

¿Cómo hablar entonces desde la sociología -y no, por ejemplo, desde una filosofía abstracta de la acción- de la creatividad que podríamos considerar como propiamente dicha: la creatividad evenencial? Mi propuesta es que

2 En este punto cabe recordar que Weber habló de la irracionalidad como un "problema" de las ciencias sociales precisamente porque ponía límites a la pretensión de explicar científicamente la acción (Weber, 1993). También es útil recordar el argumento de Z. Bauman, quien consideró a la sociología como una "ciencia de la no libertad", interesada por la sociedad como "segunda naturaleza" y, en este sentido, programáticamente determinista (Bauman, 1977). puede hacerse acercando al discurso teórico de la sociología un concepto extraño a sus matrices: el de "imaginación”. Los modelos al uso de la acción y del actor captan sobre todo la contingencia relativa, porque sus descripciones del actor están orientadas a reducir analíticamente la complejidad de la acción. Es necesario introducir en esas descripciones aquello que hace que los agentes sean capaces también de creatividad evenencial, y la noción de imaginación ofrece un recurso concreto para hacerlo. Tal es la propuesta que quiero desarrollar.

Por supuesto, no hay razón para ser excluyente, y obviamente hay otros caminos posibles. El de la imaginación tiene, sin embargo, dos ventajas a priori: que es un concepto extraño al campo, lo que hace que la proyección de sus implicancias sobre las teorías de la acción sea un terreno todavía virgen; y segundo, que es un concepto de tal envergadura y calado en la tradición filosófica que asegura un pluralismo y una densidad teórica acordes con los de las teorías sociológicas de la acción. De esta cuestión hablaré en el apartado final. En cuanto a la primera, que el terreno sea virgen no promete nada por sí mismo, salvo apertura de posibilidades teóricas, lo que es bienvenido en un terreno que, como el de la teoría social, no abunda actualmente en grandes innovaciones conceptuales.

De lo que se trata, entonces, es de reorientar el sesgo reproductivista de la teoría sociológica de la acción, insertando en sus matrices teóricas el concepto de imaginación. "Insertando" quiere decir no simplemente agregando un concepto a esas matrices, sino haciéndolo interactuar con ellas y dentro de ellas, lo que implica que no se trata de imponer un sesgo nuevo y otra vez excluyente -la acción es acontecimiento y fundamentalmente acontecimiento-, sino de ampliar su marco de referencia, incluyendo con más precisión lo que estaba excluido. 


\section{Imaginación y acción}

Lo que tenemos delante es, por tanto, un gran campo de investigación cuya primera precisión tiene que ser qué imaginación y en qué acción, esto es, de qué hablamos cuando decimos "imaginación” y en qué sentido preciso imaginación y acción pueden conectarse. Como es obvio, esta pregunta requiere precisiones que solo pueden lograrse en el interior de enfoques concretos, pero me gustaría abordarla de un modo general, con una suerte de gramática pura, lo que tiene como objetivo visualizar mejor el campo de análisis. Me voy a valer para eso de dos recursos: una clarificación simple del concepto de imaginación propuesta por Lapoujade (1988: 102-118) y un panorama general de la teoría sociológica de la acción que elaboraron hace unos años Emirbayer y Mische (1998). El siguiente cuadro integra ambas cosas y guía la argumentación posterior.

Cuadro 1. Niveles de la imaginación y aspectos de la acción

\begin{tabular}{|c|c|c|c|c|c|c|}
\hline \multirow{2}{*}{$\begin{array}{l}\text { Niveles de la } \\
\text { imaginación }\end{array}$} & \multirow{2}{*}{$\begin{array}{c}\text { Funciones de } \\
\text { la imaginación }\end{array}$} & \multicolumn{3}{|c|}{ "Componentes" de la imaginación } & \multirow{2}{*}{$\begin{array}{l}\text { Orientación } \\
\text { temporal }\end{array}$} & \multirow{2}{*}{$\begin{array}{l}\text { Aspectos de } \\
\text { la teoría de } \\
\text { la acción }\end{array}$} \\
\hline & & $\begin{array}{l}\text { Presencia } \\
\text { del objeto }\end{array}$ & $\begin{array}{l}\text { Conocimiento } \\
\text { del objeto }\end{array}$ & $\begin{array}{l}\text { Existencia } \\
\text { del objeto }\end{array}$ & & \\
\hline $\begin{array}{l}\text { Percepción / } \\
\text { Problematización }\end{array}$ & $\begin{array}{l}\text { Completa, } \\
\text { interroga }\end{array}$ & Sí & Sí & Sí & Presente & $\begin{array}{l}\text { Evaluación } \\
\text { práctica }\end{array}$ \\
\hline Memoria & Actualiza & No & Sí & Sí & Pasado & Iteración \\
\hline Anticipación & Proyecta & No & No & Sí & Futuro & Proyectividad \\
\hline Creación & Inventa & No & No & Posible & Futuro & Proyectividad \\
\hline
\end{tabular}

La imaginación puede definirse, en primera instancia, como la capacidad de crear imágenes al margen de la experiencia inmediata de los sentidos. Por lo tanto, puede establecerse una gradación de niveles de imaginación según que las “imágenes" se alejen más o menos de lo dado; una gradación que, además, se mueve en un eje temporal. En el primer nivel (la percepción), la imaginación sintetiza o completa el conocimiento de un objeto o fenómeno presente. Puesto que ninguna información sensorial cubre por completo un objeto, la imaginación es indispensable y participa en cualquier acto perceptivo. Un fenómeno complementario a este, pero importante de distinguir, es el de la "problematización", que ocurre cuando lo dado no puede asimilarse a algo conocido. Allí la función de la imaginación es proponer respuestas tentativas (¿es X lo que veo?) y de esta manera ir también más allá de lo dado.

En el segundo nivel encontramos a la "memoria", donde la imaginación trae al presente objetos del pasado. Son, como se ve en el cuadro, objetos "conocidos" y "existentes" (no extraños ni puramente fantásticos), pero ahora ausentes. Por ende, la distancia es mayor que en la percepción y en la interrogación, y tanto más cuanto más complejo sea lo recordado y más lejos se encuentre en el tiempo. En tercer lugar, ya no hacia el presente o hacia el pasado, sino hacia el futuro, la imaginación desempeña un rol de "anticipación", campo en el que también hay diferencias de grado. Desde lo dado inmediatamente puedo anticipar con la imaginación lo que sucede en conexión inmediata con este presente (la dirección que tomará la pelota 
golpeada por la raqueta de mi adversario y que ahora veo moviéndose en una determinada dirección), pero también puedo anticipar cursos de acontecimiento de un futuro más lejano (preveo mi situación en la vejez), con lo que la importancia de la imaginación (lo que aporta a la experiencia) aumenta.

En todos estos niveles la imaginación tiene sobre todo una función epistémica: participa en la producción de algún tipo de conocimiento y colabora en la tarea con otras "facultades" cognitivas, como la conceptualización y la percepción. En el último nivel la imaginación se relaciona con el futuro, pero ya en una función plenamente creadora: no completa la aprehensión de un presente desplegándola hacia el futuro, sino que "inventa" un futuro "posible". Se relaciona con "objetos" que no solo no están presentes ni son conocidos, sino que son "inexistentes". En este nivel, la imaginación se funde con la fantasía y, en general, con la capacidad de creación. Y aunque incluye un valor que puede considerarse epistémico, ni se agota en el conocimiento ni es fundamentalmente conocimiento, sino precisamente imaginación creadora en el sentido que puede considerarse fuerte de la palabra.

Ahora bien, estos niveles de la imaginación se mantienen en el plano de las actividades "mentales"; ¿de qué manera trascienden ese carácter y competen concretamente a la acción? El artículo de Emirbayer y Mische nos ahorra mucho camino en este punto, porque ofrece un panorama de las teorías sociológicas de la acción, ordenándolas también desde una perspectiva temporal. $\mathrm{Su}$ punto de partida es la inquietud que suscitan las teorías de la acción por su parcialidad (teorías normativistas o racionalistas, teorías del conocimiento práctico o de la conciencia reflexiva, etcétera), y ordena estas parcialidades precisamente en un eje temporal que permite distinguir acentos en el presente, el pasado o el futuro, al igual que apreciar el interés y la factibilidad de integrarlos. Así, hay teorías que subrayan el peso del pasado en la acción, como las teorías normativas clásicas $\mathrm{y}$, en general, las disposicionales (habitus, aculturación, etcétera); en cambio, hay teorías que ponen el acento en el futuro (más precisamente en la capacidad de la acción para relacionarse con los sucesos por venir: típicamente la Rational Choice); también hay teorías que centran su atención en el presente y en las capacidades para gestionar situaciones nuevas o desafiantes (algunos aspectos de la acción comunicativa o ciertas teorías feministas).

Partiendo del análisis mediano de la temporalidad, los autores proponen integrar las distintas perspectivas en la idea de que toda acción se vincula desde el presente con el pasado y con el futuro. Habría, en este sentido, tres grandes dimensiones de la acción: respectivamente "iteración”, "evaluación práctica” y "proyectividad" (pasado, presente $\mathrm{y}$ futuro), que funcionan como las cuerdas de un instrumento musical: hacen juntas una melodía, la cual las necesita a todas, pero tiene siempre un tono dominante. Desde esta matriz se puede releer y reordenar, a juicio de los autores, el panorama de la sociología de la acción y de sus múltiples relaciones.

La orientación temporal proporciona, entonces, la clave para conectar la imaginación con la teoría de la acción. Lo que muestra el cuadro es la gramática elemental de esa conexión. En el eje del presente, la "evaluación práctica”, es decir, la capacidad de los agentes de gestionar situaciones nuevas, se conecta con la función perceptiva y, sobre todo, "problematizadora" de la imaginación. En el eje del pasado, lo que la acción debe a la inercia de las disposiciones aprendidas se conecta con las funciones mnémicas de la imaginación. En el eje del futuro, la capacidad de la acción de proyectar su propia inserción en el 
mundo se conecta con la función anticipatoria de la imaginación. Y también en el eje del futuro, la "proyectividad" de la acción se conecta con la imaginación como creación/ invención de realidades posibles. "Se conecta" quiere decir, en todos los casos, que las descripciones y análisis de las diversas teorías de la acción pueden potencialmente enriquecerse con las que aporta el análisis de la imaginación. Pero va de suyo que las conexiones no se limitan a esto: en la medida en que las orientaciones temporales de la acción van juntas, cada una se relaciona, a su vez, con todas las dimensiones de la imaginación. Así, por ejemplo, un fenómeno típico de iteración como es el habitus se conecta con la imaginación no solo mnémica sino también creadora (propuse en un trabajo anterior un desarrollo concreto de este vínculo; véase: Cristiano, 2011).

Tenemos, por tanto, una plataforma heurística para múltiples desarrollos teóricos. Pero el cuadro también permite hacer una distinción importante para nuestro problema y para la pretensión de tratarlo desde el punto de vista de la imaginación. En primer lugar, hay una creatividad que tiene que ver con la función epistémica de la imaginación; percibir, interrogar, recordar o anticipar son actividades que siempre encierran algún grado de creatividad, en la medida en que siempre convocan a la imaginación. Sin embargo, es una creatividad que corresponde a la acción de un modo indirecto, puesto que acontece en procesos "subjetivos" que no necesariamente se plasman en acciones. En segundo lugar, hay una creatividad a la que podríamos llamar "creatividad-proyecto", que se corresponde con la dimensión anticipatoria de la imaginación y que si bien se mantiene en sus funciones epistémicas, se conecta con la acción de un modo pleno: sirve a la acción y de algún modo se subordina a ella. En tercer lugar, la imaginación estrictamente creadora (la que inventa lo que no existe) puede ser también una actividad mental, pero puede convertirse, por intermedio de la expresión, en acción creativa en un sentido sustantivo. El arte, en sus diversas formas, es el ejemplo clásico, pero no hay razón para limitarse a él; también es una acción creativa en este sentido la de quien propone a otros una forma nueva de institución.

A simple vista parece claro, aunque requeriría un análisis ad hoc, que la segunda de estas creatividades es la que ha predominado en la teoría sociológica de la acción. Si se da por cierta, esta constatación complementa lo antedicho sobre la creatividad relativa y la evenencial, pues esta última es precisamente la que se manifiesta como invención de posibilidades inéditas. Más allá de esto, la expresión "creatividad de la acción” designa, según lo anterior, por lo menos tres cosas notoriamente distintas: la riqueza con que se carga la percepción o el "registro" del mundo, la proyección imaginativa de cursos posibles de acción y la concreta creación imaginaria de mundos posibles.

\section{Perspectivas sobre la imaginación}

Esta aproximación a la imaginación es de todos modos bastante elemental. Dije al principio que una de las ventajas del concepto es su densidad y diversidad filosófica, por lo que me gustaría dar una idea de esa complejidad, para avalar por otra vía el interés de la propuesta. A diferencia de lo que pasa con la sociología, casi ninguna empresa filosófica ha dejado de hablar de la imaginación (pueden verse presentaciones extensas en Lapoujade, 1988; Warnock, 1986 y Kogan, 1986), por lo que la tarea es casi imposible en poco espacio. Sin embargo, si nos limitamos a algunas líneas de pensamiento especialmente próximas a la sociología, creo que pueden diferenciarse tres grandes matrices de reflexión, según se haga de la imaginación un aspecto del funcionamiento de la conciencia, del lenguaje 
o de la psique. La incidencia de estas tres cuestiones en la historia de la sociología da una idea intuitiva de la multiplicidad posible de sus alcances, y si a eso agregamos que cada uno ofrece también una diversidad de perspectivas, el mapa teórico se hace prácticamente inagotable. Para anclar un poco esa dispersión voy a limitarme a ilustrar, con ayuda de pocos textos pero importantes, el sentido de esas matrices y algunos caminos por los que pueden conectarse con sociologías concretas de la acción.

En el caso de la filosofía de la conciencia, la conexión más inmediata es con la fenomenología, donde Sartre $(2005,2006)$ ofreció un análisis constitucional de lo que llamó "conciencia imaginante", distinta de la "conciencia realizante". La conciencia imaginante constituye un fenómeno especial que es el de la "imagen", pero sobre todo sustenta trascendental y empíricamente ni más ni menos que la libertad humana. "El hombre imagina porque es trascendentalmente libre", pero al mismo tiempo la imaginación, en tanto negación de lo constituido como "real", es "la condición necesaria de la libertad del hombre empírico en medio del mundo" (Sartre, 2005: 257). Por consiguiente, además de una extensión sistemática del análisis de Husserl hacia la imaginación, Sartre extiende el problema de esta hacia una filosofía política. El puente más concreto de este análisis con la sociología de la acción es Schütz, quien, sin embargo, no tiene en cuenta a este Sartre en particular, aunque sí al de El ser y la nada (Schütz, 1974: 175-193). El interés de desarrollar el vínculo parece claro, sobre todo por su importancia política y en atención a que precisamente lo político ha sido un blanco de crítica hacia la fenomenología. Es de todos modos un punto, y no más, entre los muchos en que pueden tocarse filosofía de la conciencia y sociología de la acción.

En el caso del lenguaje, la obra de Ricoeur ofrece un tratamiento explícito de la imagi- nación, que se inscribe precisamente en el proyecto de trasladar la teoría del texto al análisis de la acción (Ricoeur, 2001: 169195). En pocas palabras, la tesis de Ricoeur es que "nuestras imágenes son dichas antes que vistas" (2001: 201), en el sentido de que la imaginación no se refleja en el lenguaje viniendo de otro lado, sino que ocurre en el lenguaje y por el lenguaje. Esto significa que algunos funcionamientos del lenguaje -en especial los que han sido objeto de la retórica y los estudios literarios- pueden tomarse como "ventanas abiertas al enigma de la creatividad" (2001: 24). Así, el autor aísla en concreto dos funcionamientos: el de la narración y el de la metáfora, que tienen en común el ser fenómenos de "innovación semántica", pues hacen crecer el lenguaje y su fuerza de descripción y redescripción de la realidad, y con ello enriquecen también la vida práctica y la propia acción. La tesis puede extenderse a otras dimensiones del lenguaje y se inscribe, obviamente, en el marco global del giro lingüístico.

Los trabajos de Ricoeur han inspirado a una importante escuela francesa de sociología de la acción (Quéré, Pharo, Thévenot, Dodier; un acercamiento introductorio puede encontrarse en De Ípola, 2001: 34 y ss.), que, sin embargo, no ha prestado mayor atención a estos análisis de la imaginación. He ahí un campo concreto y a mano de recepción sociológica de la imaginación ricoeuriana. No obstante, más ampliamente la idea de que el lenguaje es un medio de acceso a la imaginación invita a una relectura del modo en que los fenómenos lingüísticos han sido incorporados en diversas sociologías de la acción (por ejemplo, el análisis conversacional de la etnometodología, los usos de la pragmática que hace Habermas o los múltiples usos del segundo Wittgenstein). La hipótesis general de este análisis es que muy poco se ha atendido a las dimensiones 
estéticas del lenguaje en las que Ricoeur sitúa precisamente lo imaginario.

En el caso de la psique, el campo es mucho más amplio en ambos frentes: el del tratamiento explícito de la imaginación por el psicoanálisis y el de la apropiación del psicoanálisis por la sociología. Los nombres de Freud, Marcuse y Castoriadis pueden tomarse de todos modos como referentes, porque expresan una progresiva radicalización tanto de la importancia de la imaginación en el funcionamiento de la psique, como de su importancia social y política. Freud situó el problema en el marco de la dicotomía principio de placer/principio de realidad e hizo de la phantasia el reducto del principio del placer en la psique adulta socializada.

Textos como El malestar de la cultura o El porvenir de una ilusión expresan el carácter políticamente conservador que se le atribuye, lo que es criticado con agudeza por Marcuse (1983: 135-149) y llevado a su extremo en la psicología de Jung. Para Marcuse, el punto es que Freud conectó exageradamente la imaginación con el sustrato arcaico del subconsciente, descuidando la capacidad de la imaginación para vincularse con el futuro y para crear mundos alternativos. Castoriadis, cuya filosofía de la imaginación es posiblemente la más contundente del siglo XX, lleva al extremo este énfasis político. Para él, la imaginación no es un componente más de la psique, sino el que define su esencia, pues la psique no es otra cosa que la capacidad de producir representación, sin ceñirse a condición de ningún tipo, ni orgánica ni social. Tiene, por ende, un componente subversivo intrínseco que la convierte en "imaginación radical" (Castoriadis, 1999: 288 y ss.) y en el fenómeno "instituyente" por excelencia. En este sentido hay historia, y hay cambio social porque hay imaginación. La presencia del psicoanálisis en la teoría de la acción es muy variada, pero en escasa medida ha asimilado este tipo de reflexiones sobre la imaginación. Puede traerse a la memoria a Parsons, quien representa exactamente el uso contrario del psicoanálisis (con énfasis en la "introyección" y en la personalidad como un sistema en equilibrio), y más recientemente a Habermas o a Giddens, interesados también más en los procesos de socialización de la psique que en su potencia instituyente.

Por supuesto, deben tomarse estas pinceladas como lo que son: intuiciones o direcciones de análisis, que tienen solo el valor de mostrar el interés de la propuesta. Nótese, sin embargo, que lo que tienen en común, a pesar de sus diferencias, es conectar la imaginación con la crítica y con el cambio social, con lo que volvemos al principio de nuestro recorrido y a la advertencia del peligro de hacer de la creatividad una celebración liberal del individuo capaz. Si hay algo que la creatividad de la acción no es desde este punto de vista es eso, y si hay algo de lo que nos alejan los autores que acabo de evocar es de cualquier género de individualismo egocéntrico. Valga esto para dejar abierta una discusión que también es crucial, pero que no hay más remedio que postergar: la del vínculo entre la creatividad de la acción con los procesos de interacción social y con la acción colectiva.

\section{Conclusión}

En este apretado recorrido he ofrecido los rudimentos de (i) un diagnóstico de la tradición sociológica sobre la acción, (ii) una aclaración operativa del concepto de "creatividad" y (iii) los lineamientos globales de un tratamiento de la creatividad en términos de imaginación. Por supuesto, el modo condensado en que lo hice deja sin formular muchísimos detalles, pero aspiro a que esa mirada general sea útil para estimar las posibilidades del enfoque -que es uno entre múltiples-de la creatividad de la acción. Una última aclaración resulta indispensable para concluir: la 
creatividad de la acción se vincula, como acabamos de ver, con el cambio social, pero no es su equivalente. Lógicamente, creatividad y cambio son independientes, puesto que es posible la creatividad sin cambio y también lo inverso. La aclaración del vínculo entre ambas cuestiones puede considerarse, de todos modos, como el objetivo último y más importante de un interés sociológico por la creatividad de la acción, y quizás también el signo de identidad de un enfoque sociológico y crítico de la creatividad.

\section{Referencias}

Bauman, Z. (1977). Para una sociología crítica. Buenos Aires: Marymar.

Castoriadis, C. (1999). Hecho y por hacer. Buenos Aires: Eudeba.

Crespi, F. (1997). Acontecimiento y estructura: por una teoría del cambio social. Buenos Aires: Nueva Visión.

Cristiano, J. (2010). La creatividad de la acción, el modelo joasiano y la cuestión de lo imaginario. Nómadas, 26, 267-285.

Cristiano, J. (2011). Habitus e imaginación. Revista Mexicana de Sociología, 73(1), 47-72.

Dawe, A. (2001). Las teorías de la acción social. En Botomore, T. y Nisbet, N. (Eds.). Historia del análisis sociológico. Buenos Aires: Amorrortu.

De Ípola, E. (2001). Metáforas de la politica. Buenos Aires: Homo Sapiens.

Dubet, F. (2006). El declive de la institución. Bercelona: Gedisa.

Emirbayer, M. y Mische, A. (1998). What is agency? American Journal of Sociology, 103(4), 962-1023.
Ferrater Mora, J. (1964). "Modalidad". En Diccionario de Filosofía. Buenos Aires: Sudamericana.

García Selgas, F. (1999). "Introducción a la des/re construcción del agente social". Política y Sociedad, 30, 5-10.

Iglesias de Ussel, J. y Herrera Gómez, M. (Coords.) (2005). Teorías sociológicas de la acción. Madrid: Tecnos.

Joas, H. (2005). The Creative of Action. Chicago: Chicago University Press.

Kogan, J. (1986). Filosofía de la imaginación. Buenos Aires: Paidós.

Lapoujade, M. (1988). Filosofía de la imaginación. México: Siglo XXI.

Marcuse, H. (1983). Eros y civilización. Madrid: Sarpe.

Ricoeur, P. (2001). Del texto a la acción: ensayos de hermenéutica II. México: Fondo de Cultura Económica.

Sartre, J. (2005). Lo imaginario. Psicología fenomenológica de la imaginación. Buenos Aires: Losada.

Sartre, J. (2006). La imaginación. Madrid: El Edhasa.

Schütz, A. (1974). El problema de la realidad social. Buenos Aires: Amorrortu.

Tatarkiewicz, W. (1988). Historia de seis ideas: arte, belleza, forma, creatividad, mímesis, experiencia, estética. Madrid: Tecnos.

Warnock, M. (1986) La imaginación. México: Fondo de Cultura Económica.

Weber, M. (1993). El problema de la irracionalidad en las ciencias sociales. Madrid: Tecnos.

Williams, R. (2000). “Creación”. En Palabras clave. Un vocabulario de la culturay la sociedad. Buenos Aires: Nueva Visión. 